\title{
Paradoxical Effect of the Cultural Distance on the Attractiveness of the Territorial Morocco for the French FDI: of Acculturation in the Intercultural Misfit
}

\author{
Sophia BEKKAOUI \\ Doctor in economics and management \\ Faculty of Economical and Social Legal Sciences, \\ First Mohammed University. \\ FSJES, UMP-Oujda \\ Morocco
}

\begin{abstract}
The purpose of this communication is to respond to the following questions: How do we explain the implantation of foreign firms on territory in spite of a cultural distance between the latter and their countries of origin? The national culture reflects-t-it its cultures regional/local? Generally, the major concern of the firm is the intercultural fit (intercultural compatibility).

This article proposes, through the analysis of cases of french FDI (Foreign Direct Investment) localized in Morocco and a survey of 30 Managers to identify the degree of compatibility between the managerial cultures of the French subsidiary established and of the implantation site chosen. The intercultural fit/misfit is measured by the calculation of the cultural distance via including the use of the cultural dimensions of Hofstede. This communication is part of the reflection of the intercultural management for the firms in the choice of their strategy of localization.
\end{abstract}

Key words: Cultural Distance, Choice of The Site of Implantation, Performance of the MNF, Intercultural Management, Intercultural Fit/Misfit.

\section{INTRODUCTION}

In the face of an increased demand for the FDI, multinational firms are evidence of a selectivity of more and more accentuated in their choice of localization. As their capacity assessment and selection is strengthened, the consequence is the classification of the territories according to their attractiveness for FDI, classification which delimits a side the most attractive countries and on the other hand those who attract a limited number of foreign firms. This classification introduced new cultural dimensions and managerial of selection to hand the traditional ones, economic and socio-political.

The choice of location represents a major strategic decision and determinative of the performance of the firm. Yet, many failures to the international are due to a lack of knowledge on the specificities of foreign territories and sites of implantation.

In addition, the decision of localization of a multinational company can be described as a sequence of geographical selection in which the company chooses to first a country, and then a region in the interior of this country. It corresponds to the selection process of the location considered optimum for socio-economic activities specific.

In this regard, a multitude of sites of alternative implementation present themselves to a company within a national territory, among which it is not always easy to make a choice in the light of economic factors alone. It does not have perfect knowledge on the conditions for the exercise of its activity on the new location chosen. Therefore, the location on a new geographical site is able to conceal the costs cover up non-negligible, especially if it is a question of a first implantation on a foreign territory. Therefore, the selection of a new site of implantation is an exercise singularly delicate, during which are necessary trade-offs between the requirements varied and sometimes even opposed.

Such situations are unfavorable to decision-makers, to put in place of the formalities of economic optimization. Accordingly, the controversy to select a new location cannot be resolved solely on the basis of costs. By the fact, it is large, according to the inventory of the literature, to examine the cultural similarity/dissimilarity of managerial practices between the territory of implantation and the one of origin. Therefore, the choice of the site of implantation depends on ample of the intercultural adaptation of the firm. In addition, the FDI confronts the company to the distance between his country of origin and the country in 
which it wishes to develop. In this case, it is facing difficulties in respect and understand some aspects of managerial practices of the new country.

In this article, we study the strategy of geographical localization of FDI french in Morocco. We are trying to understand their choice of implantation sites under the angle of cultural contingency. More specifically, we are studying the influence that could have the managerial culture of Morocco on the strategy of the geographical localization of the french FDI.

According to the census of the literature on the decision of localization, the latter is strongly linked to the cultural distance between the territory of implantation and the territory of origin of the subsidiary. As much to say a strong distance to negatively influence the attractiveness of the territory. In effect, the subsidiary will have difficulties to operate in a cultural context differentiated. As well, it will not have the ability to adapt its social behavior and managerial to create good working conditions and a social climate motivating. This will have a negative effect on his performance. So, the mother organization will abstain to choose the territory for the implantation of its business.

Thus, for our case, inescapably The two french cultures and moroccan should be compatible meaning that there is no place of intercultural distance. Otherwise, in the opposite case, the french multinationals do not choose Morocco as territory of implantation. Generally, the major concern of the firm is the intercultural fit (intercultural compatibility). Based on the model of Hofstede which remains the best reference, scores of different dimensions relatively to the two cultures differ where we are in the presence of a distance intercultural. Notwithstanding, the reality reveals to us that the french IDE are most localized in Morocco, in particular at the level of a very limited number of moroccan regions. It is this paradoxical effect which constitutes the main concern of our reflection. Of where our problem: How the managerial culture affects the strategy of localization of MNF?

As well, the objective of our article is to understand the paradox of the cultural distance national/local cultural proximity or even misfit national intercultural/fit local intercultural. In other words, how do we explain the implantation of french FDI on the Moroccan territory in the face of the cultural distance between Morocco and France.

In this article, we highlight, in the first place, the issues of cultural differences on the performance of MNF in distinguishing between the managerial practices at the international as well as the different dimensions of measurement of the cultural distance. In the second place, an empirical study is conducted in the context of Morocco, to check the compatibility between the culture of the subsidiaries and the local culture and to draw by the result of the findings and recommendations.

\section{Issues of cultural differences on the performance of firms: Between styles of management at the international and national cultures}

The intercultural management is essential for the firm except certainly the adequacy between the territorial offer and demand entrepreneurial. Thus, a first axis will present the two modalities of management at the international in demonstrating the effect of cultural differences on the choice of the managerial practice of the MNF. While a second will be relative to the identification of dimensions to measure the cultural distance.

\subsection{Managerial practices to the international}

The literature notes two dominant approaches of managerial practices to the international. On the one hand, the approach known as universal, following a logic of convergence, calls for the negligence of the differences in the national context and the universality of the modalities of the management to the international. On the other side, we have the contingent approach completely contextual, having a logic of divergence, which takes into account the context and the differences of any kind in which the practices will be applied and tends to adapt to its environment.

\subsubsection{Universalistic approach}

This approach includes the good practices which allow of manager at the international in any context, while applying the principle of universality of the techniques and principles of management in all situations. In other words, the universalistic approach advocates the existence of a series of best practices and a better way to do (one best way) which can lead to the performance of the organization if they are implemented, regardless of the context in which the organization operates.

As much to say, this classical approach of management stipulates that companies can be managed in the same way as a national or international scale (homogeneity of contexts and convergence of practices).

Of this fact, managerial practices are developed, formalised and exported as of the hardware products to foreign countries (Mutabazi et al., 1994) [1]. These remarks are justified by the existence of identical competitiveness: companies are increasingly faced with a competitive environment similar and global.

In this framework, the organizations adopt a form of management totally comprehensive world-wide while ignoring the national differences (Dupriez and Simons., 2002) [2]. 
Notwithstanding, these practices may not be adopted in the dark, but they must adapt to the contextual realities of the country including the cultural elements.

The non taken into account of the cultural dimension by the firm may cost him dear by the suite, it can lead to negative effects (failure of communication intra-organizational, internal conflicts more numerous, staff too stressed or unmotivated...). It is essential to analyze the culture of the host country nevertheless, it remains insufficient to succeed because there are other contextual factors.

Which may have an effect on the pane intra-organizational of the firm to the extent where if it opts for a universal approach, this will generate a certain cultural heterogeneity and suddenly, in seeking an organizational performance, it will change of logic to go toward that contingent to taking into account the contextual factors of the host country to achieve a cultural homogeneity with the national culture.

\subsubsection{Contingent approach}

Contrary to the hypothesis of convergence and universality, the contingent approach stipulates that organizations must take into account, and even to submit to the reality and the requirements of the local context. According to this approach, the adaptation of the organization to its context is a key factor in organizational success. It is important and even essential for the achievement of the objectives set and achieve organizational performance.

According to the culturalistes, managerial practices usually effective in a given context, are not always elsewhere. They can sometimes even be questioned in the case of a change of the cultural environment because they are intimately related to the national cultural identity, even regional.

According to Hofstede (1987) [3], each country develops his own management system and this for three reasons: existence of different institutions supported on their history, the symbolic value of the nationality (personal identity) and finally the cultural factors (influencing the modes of thought).

In this logic of the diagnosis of factors influencing organizational performance, the emphasis is more particularly on the cultural context as being the key factor of the organizational efficiency (Naguib, 2006) [4].

Of this fact, the factors of order cultural and institutional frameworks represent a source of divergence of practices in organizations in general and in the multinationals in particular. As well, it is no longer appropriate to speak of a transfer and a copying of managerial knowledge from one unit to another located in a different country. By their heterogeneous contexts, the subsidiaries can in turn enrich and develop the practices of the global network of the multinational (Taggart, 1998) [5]. The transfer of knowledge from the seat to the subsidiaries of a hand and the «reverse-transfer» (from the subsidiary to the seat or other units) on the other hand, give birth to a hybridization. This combination of resources and knowledge becomes a source of enrichment and competitiveness of firms.

In parallel to these two approaches, the firms are faced with two different situations dependent on the type of their managerial practice, if they converge to the same culture, there will be a destruction of cultural diversity. Otherwise, in the contrary case, they are in the presence of a divergence and from there a presence of differences. Accordingly and in a manner successive we are witnessing a cultural homogeneity/heterogeneity. The first posture can promote a good climate for the resolution of problems encountered in the presence of a degree of integration to the new culture, leading subsequently to a performance of the firm. The time that the second posture, in most situations, generates a risk confrontational between the firms and the host territory because, cultural differences create an offset at the level of interpersonal communication of the fact that the message sent by the transmitter is apprehended by the receiver, in function of its own cultural codes, which generates a change of the meaning of the message. In short, there is no connection between what had for objective to say the transmitter and what has understood the receiver.

Thus, the cultural language of a given community vehicle a set of symbols whose served is understood that only by the members of the Community (Ntabona, 2009) [6].

Of this fact, the national culture is an element major explanatory of the divergence of managerial practices that appear in the subsidiaries of the same multinational organization.

In effect, for the firm, issues of cultural differences do not relate solely to this level of national culture. Some work indicate that the differences in organizational culture have an influence, which may even exceed that of national differences (Pothukuchi $\boldsymbol{e t}$ al., 2002) [7]. Other show that the culture of profession can also influence the relationship between seat and subsidiary (Viegas Worst, 2008) [8]. As well apprehended, the cultural differences thus tend to overshadow the multiplicity of levels of analysis or even their articulation. The impact of cultural differences on the performance of the MNF is relatively linked to cultural distance, a combination between of proximities professional cultural organizational and on the one hand, and a distance national cultural of the other part. We are talking then about «cultural distance global». In this logic, all cultures are entangled.

In effect, this cultural distance is calculated according to the dimensions of Hofstede (1991) mainly, but we have added other for a more complete analysis, based on the work of Hall (1979) and Trompenaars (1994). 


\subsection{Strategy of localization of the MNF and choice of the site of implantation}

The choice of the site of implantation of the FDE confronts the working culture of the firm to the local culture of the site. In a context of organizational performance of the intercultural, the strategy of localization of MNF is developed in a context of taking account of cultural differences.

\subsubsection{Strategy of localization of the MNF in the face of cultural differences}

The strategies of the localization of MNF depend on the advantages specific to the firm, but also the conditions offered by the countries hosting them. In addition, the strategy of multinational localization implies that each subsidiary has a separate strategy for each of its foreign markets. In a cultural environment differentiated, the performance of firms being linked to that of its subsidiaries on the site of implantation will therefore, the taking into account of the cultural differences between their country of origin and the chosen site.

Therefore, if necessary management practices intercultural dialog, because they affect the behavior of actors, and therefore on the performance of the firm. In addition, according to the census of the literature on the choice of geographical location of the firm, it is strongly linked to the cultural distance between the territory of implantation and the territory of origin of the subsidiary.

In this context, the research work in international management on the link between the cultural distance and the performance of the MNF show results rather mixed. However, despite the many controversies, first, the cultural distance is often mobilized in the literature to measure the degree of remoteness cultural (Luo and Shenkar, 2011) [9]. Secondly, companies will seek to locate their activities in countries culturally close to their countries of origin to increase their chance of success (Slangen and Tulder, 2009) [10]. The cultural distance measure the differences in beliefs or values between two organizations or individuals from two different countries. It more complex as well, the activities of the MNF where she is facing the dilemma of transfer of knowledge of his country of origin to the host country and its adaptation in the face of a new culture. The cultural remoteness increases the environmental uncertainty [9].

At this level, the majority of the research relating to the study of the impact of the cultural distance on the performance of the MNF, focuses on the differences of national culture. Yet, the issues of the cultural distance for the MNF do not relate solely to this level, where the differences in organizational culture have an influence, which may even exceed that of national differences (Pothukuchi et al ., 2002) [7]. Other research shows that the culture of profession can also influence the relationship between headquarters and subsidiary (Viegas Worst, 2008) [8]. In effect, a subsidiary may not be efficient if it adapts well to the culture of the site of implantation. In contrast, a subsidiary poorly adjusted is reluctant and unfit to accept the behaviors and norms of the inhabitants and of the organizations of the site.

In this perspective, the Intercultural compatibility of managerial practices should allow a performance of subsidiaries on the site of implantation and the deployment of specific skills rooted in the cultural difference.

Arises when, the problem of the adaptation of the organizational characteristics of these subsidiaries to the cultural values of the site of implantation, in their choice of geographical location, which questioned the ability of the organization of the subsidiaries to perform at work in the face of cultural differences while considering their managerial culture.

Cultural adaptation is a process that may be influenced by many variables. In this article, our contribution focuses on a single variable: cultural distance.

It is as well that our work will focus on the apprehension of the strategy of localization of french companies and their geographical distribution on the Moroccan territory, in a context of measurement of the cultural distance between the subsidiary and the site of implantation.

In other words, the choice of the implantation site for a company is linked to its performance in the face of cultural differences, particularly to its performance in the work. To do this, the measurement of the cultural distance is a determinant of intercultural fit.

\subsubsection{Measurement of the cultural distance}

Generally, the main theory by which is measured the cultural distance is that of Hofstede. In addition, we advocate that it is useful to resort to other cultural dimensions for a more reliable measure. So, we are studying apart from the theory of Hofstede, those of Trompenaars and Hall.

The theory of Hofstede is based on five main cultural dimensions. The first dimension is linked to the distance hierarchy that can be either low or high. It measures the degree of inequality within the society and the degree of acceptance of an unequal distribution of power. With regard to the second dimension, individualism/collectivism, it demonstrates the degree of dependence of individuals in relation to the collective. For the third cultural dimension, masculinity is relative to the level of distribution of roles emotional between the two sexes toward work, the confrontations and the achievements... Also, the degree of uncertainty is the fourth dimension of Hofstede, he studied the attitude by report to the uncertainty in the life. The last cultural dimension, the LOT (Long Orientation Term) highlights the perception of the time horizon that can be either on the long or the short term. 
While this author, the pioneer of research relating to the study and management of the cultural differences between countries, examines how the cultural specificities of a countries to influence the management of the organization, its corporate culture and the style of the work of its employees, Fons Trompenaars (1994) [11] specifies more precisely the cultural dimensions influencing the behavior of the people of different nations. His theory is based on three aspects: the relationship of an individual to the nature, time and to other people.

Concerning the report of the environment related to the control of the environment, it is the object of a orientation internal or external. While the second aspect related to the report at the time, the temporal orientation is studied in relation to the ability to do several things at once or on the contrary be limited to only one. As well, it may be either sequential or synchronic.

With regard to the latter aspect, the relationship of an individual with others, it is considered relatively to different dimensions, where Trompenaars distinguishes five. The universalism/particularism that differentiates the importance granted to the general rules or to personal relationships. As regards the second dimension, it is attached to the individualism/collectivism (importance given to itself to versus group). Has these two dimensions, adds the objectivity/subjectivity that is studying the degree of tolerance to the expression of the emotions. Apart from this, the status attributed/acquired status constitutes the fourth cultural dimension of Trompenaars, student the importance given to the achievements for the acquisition of the status. As to the last dimension relating to the study of the report of the individual with others, it is relative to the diffuse commitment/limit, which discerns the degree of commitment to a situation or a person. In summarizing, some dimensions are very similar to those of Hofstede. Unlike him, the dimensions of Trompenaars are identifiable more easily, even during the first contact with foreigners. This model could be useful for the firms to be able to better understand the cultural differences in organizations, as well as to reduce the number of misunderstandings and conflicts.

As to the third theory of Edward T. Hall, he is interested in the link that exists between the culture and management, based as well on the observation of behavior to demonstrate that culture determines the way in which individuals perceive their environment. According to this author [12], these lines are classified according to three dimensions: the time, space and the context of the communication.

For the first dimension, according to the extent to which people perform a single task at a time or several simultaneously, their culture is respectively monochrone/polychrone.

Concerning the second cultural dimension relative to space, the latter can be either close or remote. This is a function of the extent to which people are comfortable with the sharing of the physical space with the other. While the context of communication being the third and last dimension, it is weak or strong compared to the extent to which the context of a message is as important as the message itself.

This first axis highlights the scope of two main dimensions in the decision of geographical localization of firms in the face of cultural differences. The first dimension is linked to managerial practice adopted by the firm, while the second is relative to the cultural distance between his country of origin and the host country. In this regard, this second dimension is the main indicator of the territorial attractiveness. In what follows, we are looking at the case of the two french and morrocan cultures, more precisely the effect of their articulation on the strategy of localization of french FDI.

\section{Strategy of localization of the french FDI in Morocco by the yardstick of cultural distance}

\subsection{Cultural distance between Morocco and France according to the model of Hofstede}

Hofestede has established the indices for each cultural dimension where the value " 0 " means the value of the lowest, while that of "100" presents the highest result possible. Therefore, the higher the index is higher, the more the people accept the particularities of the dimension allocated. The table 1 below illustrates the cultural dimensions of the two countries: France and Morocco, according to the model of Hofstede.

Table 1. Indices of the cultural dimensions of Hofstede [13]

\begin{tabular}{|l|c|c|c|c|c|}
\hline \multirow{2}{*}{ Country } & \multicolumn{5}{|c|}{ Cultural Dimensions of Hofstede } \\
\cline { 2 - 6 } & Power & Individualism & Masculinity & Uncertainty & LTO \\
\hline France & 68 & 71 & 43 & 86 & 63 \\
\hline Morocco & 70 & 46 & 53 & 68 & 14 \\
\hline
\end{tabular}

The french culture, depending on the model of Hofstede is marked by the following characteristics: a great distance hierarchical with an index of 68; a society rather individualistic (index of 71) and of women with an index of 43 . In addition, it has a strong control of the uncertainty (86) with a long-term orientation (63). 
In the Moroccan culture, the hierarchical distance is also large with an index of 70 , both in society and in the business. With regard to the second dimension, the moroccan cultural context is rather collectivist (index of 46). With regard to the dimension of masculinity, Morocco has an index of 53 where it presents itself as a society of men.

Furthermore, the moroccan society accepting the destiny immanent to the religion, is located at a low level in relation to the dimension control of the uncertainty. For the last dimension LTO, the moroccan cultural context is oriented toward the short-term (index of 14).

In its reflection, Hofstede (1980) measured the dimensions of the national culture of the two countries, Morocco and France, according to the cultural dimensions: the hierarchical distance, individualism, masculinity, the degree of uncertainty and the LOT. For our part, our main objective is to try to understand the strategy of geographic localization on the Moroccan territory, by French investors. In this regard, as we can see, the comparison of the different cultural dimensions highlighted a distance between the two cultures french and moroccan. Rationally, this intercultural distance would have a negative impact on the decision of localization of french companies. In other words, these do not choose Morocco as territory of implantation. Notwithstanding, the reality is quite contradictory to this observation, where the french companies constitute the main country investor in Morocco.

At the national level, the geographical areas with a strong attractiveness of french FDI are Casablanca and Tangier. It is as well that they have been selected as the two areas of study in our empirical approach. Having said this, our study will focus on foreign direct investment recently established, on the period 2011/2016.

In addition, the original study of Hofstede did not include data concerning the moroccan regions themselves. It is thus that we pretend to measure the cultural distance existing between the subsidiary established and the site of implantation chosen or even Tangier/Casablanca.

As well, we are conducting a survey on the cultural dimensions of these two sites chosen in order to check the compatibility between intercultural the subsidiary and the site (intercultural fit/misfit).

For this, our investigation is based on the dimensions developed by Hofstede but supplemented by those issued by Hall and Trompenaars.

Below, will be explained and identified the variables of our study, the methods of data collection and analysis as well as the measurement scales.

\subsection{Empirical Study «choice of the implantation site of french IDE to Morocco»: The extent of the cultural distance between the french multinationals and implantation sites chosen}

The objective of our investigation on the ground is to measure the distance between the culture of the french subsidiary established and the geographic site chosen or even Tangier/Casablanca. And this in the purpose of check if there is no cultural distance or even confirm or deny our hypothesis: the cultural distance is negatively correlated to the choice of the site of implantation. In other words, the more the distance between the culture of the subsidiary and that of the implantation site is high, lesser would be the attractiveness of this site and the reverse is true. In this regard, our variables to study are: the choice of the site of implantation and the cultural distance.

For the two variables, they are measured by a multitude of dimensions, however we have tried to combine them according to their common object of study.

In addition, there is the question of the method of collection of these data on the ground, in the measure where the method of access to the real inevitably results from the positioning epistemological and of methodological research. We have chosen the questionnaire where we favor the position of investigator on the ground and even the face-to-face (meeting with the persons concerned), because it gives the collection of a large number of responses. In effect, our questionnaire has been created from the software Sphinx and the analyzes have been made with the SPSS software 22.0.

In addition, for the Analysis of the Data Collected (ACP), the SPSS software is used as a tool for the processing of statistics for the preparation of our database. In addition, it allows the design of descriptive statistics and to develop factorial analyzes completed exploratory on our different measurement scales.

It is only after the preparation of the data collected that we could moved to their statistical analysis, to validate our hypothesis. In this regard, two main methods are distinguished: principal components analysis and the method of regression.

The ACP, to the difference of the other methods for the reduction of variables, concerns only the variables outside of the dimensions that the researcher attempts model. As well, the initial variables are substituted by new variables, referred to as main components [14]. By the fact, the basis of this analysis is the reduction of the initial variables or items in a more limited number of variables (principal components).

As a result of the ACP of various indices maintained explaining the two variables, we turn then to the test of their reliability, as well as the links between the different variables cited previously.

In our study, to statistically test our hypothesis, we use the simple linear regression, since the dependent variable is explained by a single independent variable. In parallel, for all treatments quantitative statistics, $\mathrm{c}$ is the SPSS software which is used. 
Therefore, through the various statistical treatments carried out, we deduce that the relationship between the two variables is significant with a beta of -,687 who wants to say that the cultural distance is negatively correlated to the choice of the site of implantation. In other words, respective manner, the more the cultural distance is high/low, less/plus the site of implantation would be chosen by the firm.

This said, there is no place of cultural distance between the subsidiaries of french multinationals and implantation sites (Tangier and Casablanca). But, on the contrary, the two french cultures and local level are compatible.

\section{CONCLUSION}

Our article shows that the strategy of localization of the multinational firm is influenced by culture managerial. In this context, the cultural differences have consequences on the communication between each cultural group and on the content of their messages, therefore on the understanding and the translation of those. Therefore, it is essential to analyze the culture of the host country and to measure the cultural distance between the latter and the country of origin. Generally, when there is a distance intercultural, the firm has a tendency to choose a country where its managerial culture would be more compatible.

However, our empirical study on the choice of localization of FDI french in Morocco, demonstrates a paradoxical effect. Despite the distance between the two cultures french and moroccan, french companies are established at the level of Tangier and Casablanca. This said that it is not enough only to measure the cultural distance between the two territories to judge the compatibility between intercultural the firm and the host country. Of this fact, the national culture does not necessarily reflect its regional cultures/local. Therefore, the choice of the implantation site must not simply only to measure the cultural distance at the global level (national) but rather at the local level.

From there, it is essential to measure the cultural distance that separates, not only the two cultures of the firm and the host country, the trinomial MNF /host countries/regions of the latter. As much to say, the allusion to the various determinants of the cultural distance are decisive, in an environment of different culture, in the choice of location of the MNF with the ultimate goal of their performance. The measurement of the cultural distance allows you to identify the mode of operation and management of the other or even of the implantation site on which is actually established the firm.

The implications deducted from this research are the number of six :

-The performance of the firm is conditioned by the intercultural compatibility between its territory of origin and that of home;

- The strategy of localization of the MNF in a cultural environment differentiated is linked to the intercultural fit managerial practices

-The ultimate measure of the distance national cultural of the host country alone cannot guarantee the performance of the firm;

-The choice of the site of implantation of the firm is linked to the degree of cultural distance;

-The distance national cultural is not the reflection of its local cultures;

-The choice of the implantation site is linked to the extent of the cultural distance of the binomial «company/country of origin/regions of the country of origin».

\section{BIBLIOGRAPHIC REFERENCES :}

[1]. Mutabazi, E. Altman Y., KLESTA A., POIRSON Ph. (1994). Management of human resources to the International. Paris: Eyrolles.

[2]. Dupriez, P., Simons S. (2002). The cultural resistance, foundations, applications and implications of the intercultural management. Brussels: De Boeck.

[3]. Hofstede, G. and Bollinger D. (1987). The cultural differences in the management. Paris: Editions of the Organization, p.18.

[4]. Naguib, R. (2006), "the tension between the global and the local: toward a management balancing the economic and the social", International Journal of Management, vol. 31, No. 1, pp: 48-58.

[5]. Taggart, J. H. (1998), "strategy shifts in MNC subsidiaries", Strategic Management Journal, Vol.19, No. 7, pp: 663-681.

[6]. Ntabona, A. (2009), "route of education in family in Burundi: an approach interculturatrice and complémentariste". Editions of the CSIR, collections "Culture and inculturation", $n^{\circ}$ 2, Bujumbura.

[7]. Pothukuchi, V., Damanpour F., Choi J., Chen C.C. Park S.H., (2002), "national and organizational culture differences and international joint venture performance", Journal of International Business Studies, vol. 33, No. 2, 2002, pp: $243-265$.

[8]. Viegas, worst M., (2008), "Culture of profession and post-merger integration-acquisition. The case of the integration of systems of reporting during the acquisition of Nippon Dantai by AXA", manage and understand, No 94, 2008 , pp: 55-63.

[9]. Luo, Y. and O. Shenkar (2011), "Toward a perspective of cultural friction in international business," Journal of International Management, Vol. 17, No. 1, pp. 1-14. 
[10]. Slangen AHL, Van Tulder RJM (2009). Cultural Distance, political risk, gold governance quality? Toward a more accurate conceptualization and measurement of external uncertainty in foreign entry mode research. Int. Bus. Rev., 18(3): $276-291$.

[11]. Trompenaars, F. (1994), "Riding the Waves of Culture. Understanding Diversity in Global Business," Irwin, Chicago, Ill. et al.

[12]. Hall E. (1979). Beyond the culture, original title beyond culture, translated by Marie-Hélène Hatchuel. Paris: EDN the threshold.

[13]. The Hofstede center: What about France. Available on the site: https://geert-hofstede.com/france.html (date of Consultation: 22/04/2016).

[14]. Jolliffe, I.T. (2002). Principal Component Analysis. New York, NY: Springer, 2nd edition. 